\title{
Toll-like receptor 4 deficiency causes pulmonary emphysema
}

\author{
Xuchen Zhang, Peiying Shan, Ge Jiang, Lauren Cohn, and Patty J. Lee \\ Section of Pulmonary and Critical Care Medicine, Yale University School of Medicine, New Haven, Connecticut, USA.
}

\begin{abstract}
TLRs have been studied extensively in the context of pathogen challenges, yet their role in the unchallenged lung is unknown. Given their direct interface with the external environment, TLRs in the lungs are prime candidates to respond to air constituents, namely particulates and oxygen. The mechanism whereby the lung maintains structural integrity in the face of constant ambient exposures is essential to our understanding of lung disease. Emphysema is characterized by gradual loss of lung elasticity and irreversible airspace enlargement, usually in the later decades of life and after years of insult, most commonly cigarette smoke. Here we show $\mathrm{Tlr}^{-/-}$mice exhibited emphysema as they aged. Adoptive transfer experiments revealed that TLR4 expression in lung structural cells was required for maintaining normal lung architecture. TLR4 deficiency led to the upregulation of what we believe to be a novel NADPH oxidase (Nox), Nox3, in lungs and endothelial cells, resulting in increased oxidant generation and elastolytic activity. Treatment of $\mathrm{Tlr}^{-4^{-/} \text {mice }}$ or endothelial cells with chemical NADPH inhibitors or Nox3 siRNA reversed the observed phenotype. Our data identify a role for TLR4 in maintaining constitutive lung integrity by modulating oxidant generation and provide insights into the development of emphysema.
\end{abstract}

\section{Introduction}

TLRs have been intensely studied in the context of microbial challenges, inflammation, and immune cells, but their critical role in non-infectious challenges has newly emerged. We have recently shown that mammalian TLR4 is required for survival during lethal oxidant stress resulting from hyperoxia $(1,2)$ or bleomycin-induced injury (3). However, even in the absence of injury, the lungs are required to process and adapt to the constant exposure to the inhaled environment. The lungs are exposed continuously to oxidants generated either endogenously from phagocytes and other cell types or exogenously from inhaled oxygen as well as pollutants. In addition, intracellular oxidants, such as those derived from the NADPH oxidase (Nox) system, are involved in many cellular signaling pathways. Under normal circumstances lungs can withstand the oxidant challenges imposed by the ambient environment via the presence of well-developed enzymatic and nonenzymatic antioxidant systems (4). However, when the balance shifts in favor of oxidants, from either an excess of oxidants and/or depletion of its antioxidant responses, oxidative stress occurs. We postulated that TLR4 mediates important antioxidant responses in the lung and that TLR4 deficiency would therefore lead to altered responses to oxidants in the ambient environment. We performed histopathologic and morphometric analyses of lungs isolated from WT and $\mathrm{Tlr}^{-/-}$mice from 1 month to 12 months of age. To our surprise, the lungs of $\mathrm{Tlr}^{-/-}$mice exhibited age-related changes that resembled pulmonary emphysema in humans both histologically and functionally.

Nonstandard abbreviations used: $\alpha 1-\mathrm{AT}, \alpha-1$ antitrypsin; BAL, bronchoalveolar lavage fluid; COPD, chronic obstructive pulmonary disease; $\mathrm{C}_{\mathrm{T}}$, threshold cycle; DPI, diphenylene iodonium; EIC, elastase inhibitory capacity; GSH, glutathione; MLEC, mouse lung endothelial cell; Nox, NADPH oxidase; Nrf2, nuclear factor erythroid 2-related factor 2; $\mathrm{O}_{2}{ }^{-}$, superoxide; 8-OH-dG, 8-hydroxy-2'-deoxyguanosine; PI, propidium iodide; PPE, porcine pancreatic elastase; SAPNA, succinyl-trialanine-p-nitroanilide; TIMP, tissue inhibitor of metalloproteases.

Conflict of interest: The authors have declared that no conflict of interest exists. Citation for this article: J. Clin. Invest. 116:3050-3059 (2006). doi:10.1172/JCI28139.
Emphysema is a major subset of the clinical entity chronic obstructive pulmonary disease (COPD) and is defined anatomically as the destruction of the distal lung parenchyma and enlargement of the airspaces. Pulmonary emphysema is a major cause of morbidity and death worldwide. Although cigarette smoking has been recognized as an important factor in the development of COPD, only $10 \%-20 \%$ of heavy smokers develop clinically significant COPD. Furthermore, cigarette smoking is not a prerequisite in the approximately $20 \%$ of men who develop COPD $(5,6)$. These trends indicate that the development of pulmonary emphysema is affected by other important factors. Several candidate genes have been implicated in determining susceptibility to pulmonary emphysema: $\alpha-1$ antitrypsin ( $\alpha 1-\mathrm{AT})$ (7), macrophage elastase (8), klotho (9), surfactant D (10), microsomal epoxide hydrolase (11), and nuclear factor erythroid 2-related factor 2 (Nrf2) (12). Alterations in these genes have been shown to lead to oxidant/antioxidant or protease/antiprotease imbalances, which are pivotal to the pathogenesis of emphysema (4).

However, the precise molecular mechanisms for maintaining the normal oxidant and protease balances remain unclear. Our present study demonstrates that TLR4 deficiency led to spontaneous emphysema after the lungs were fully developed in mice (2 months of age) but in the absence of inflammatory cell influx. The lungs of $\mathrm{Tlr}^{-{ }^{--}}$mice exhibited increased oxidant stress, cell death, and elastin degradation. Mediators of inflammation and emphysema, such as IL- $1 \beta$, TNF- $\alpha$, IL-6, IL-13, IFN- $\gamma$, and VEGF, were not differentially expressed in $\mathrm{Tlr} 4^{-/-}$mice. Furthermore, there were no differences in the classic emphysema-related MMPs, cathepsins, or tissue inhibitors of metalloproteases (TIMPs). However, we have identified what we believe to be a novel Nox, Nox3, which is regulated by TLR4 in the lung. In the absence of TLR4, lung tissue as well as endothelial cells expressed increased levels of Nox3. Chemical Nox inhibitors as well as Nox3 siRNA reversed the emphysema, oxidant stress, cell death, and elastolytic activity associated with TLR4 deficiency. Collectively, our data indicate that TLR4 acts as a "molecular switch" by regulating Nox activity 


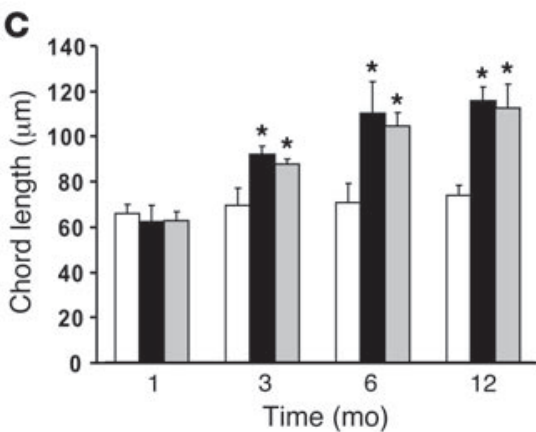

B

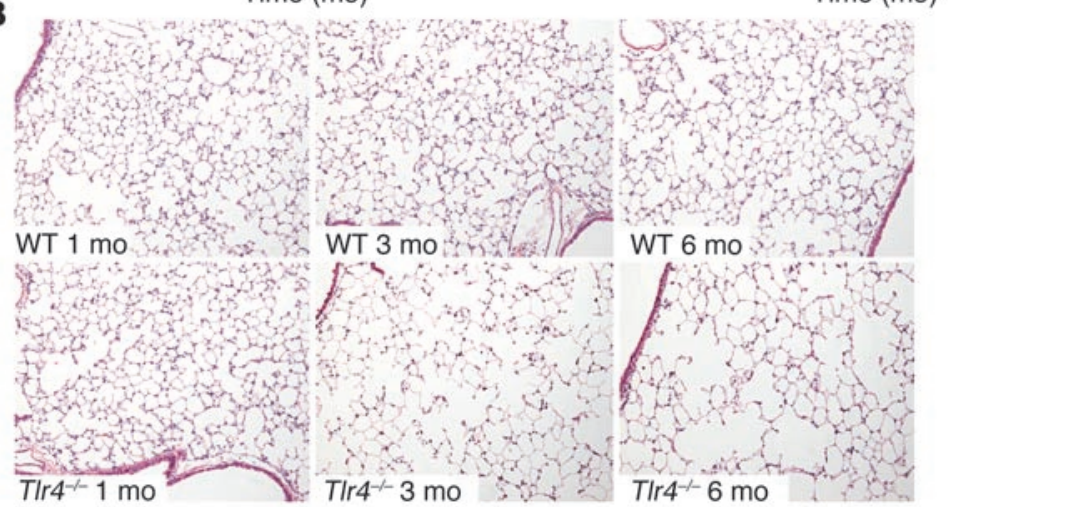

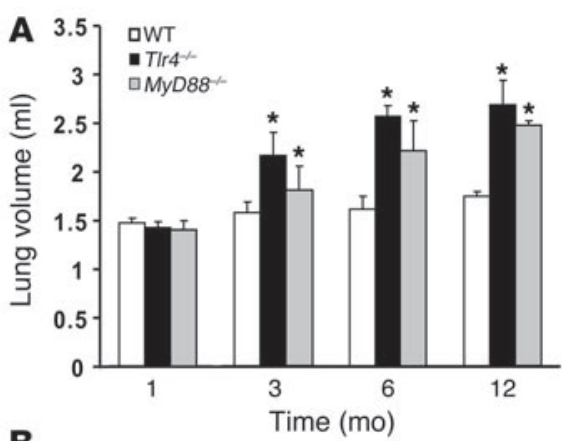

Figure 1

Spontaneous pulmonary emphysema in $\mathrm{Tlr}^{-/-}$ mice. (A) Lung volumes of WT, TIr $4^{-/-}$, and $M y D 88^{-1-}$ mice. (B) Lung histology of WT and TIr4 ${ }^{-/}$mice. Original magnification, $\times 100$. (C) Mean linear chord length in WT, TIr4 ${ }^{-/}$, and $M y D 88^{-1-}$ mice $(n=5-7)$. Data are mean \pm SEM. ${ }^{*} P<0.05$ versus respective WT values.

Tlr4 ${ }^{-/}$mice all exhibited increased lung volumes (Supplemental Figures 2-4). Mice deficient in MyD88, a central TLR adaptor protein (13), were also examined. $M y D 88^{-/-}$mice showed progressive emphysema as well, suggesting that a Myd88-dependent TLR4 pathway is responsible for TLR4-mediated maintenance of lung integrity (Figure 1, A and B).

Increased lung inflammation and the overexpression of soluble mediators such as IL-13, IL- $1 \beta$, IFN- $\gamma$, and VEGF are important in the pathogenesis of human as well as experimental emphysema (14-17). Therefore, we investigated whether $\mathrm{Tl} r 4^{-/}$mice exhibited increased lung inflammation and increased cytokines and growth factors. Interestingly, there were no significant differences in the via Nox3, thereby maintaining a critical oxidant/antioxidant balance in the unchallenged lung.

\section{Results}

TLR4 and MyD88 deficiencies result in emphysema. We investigated the role of TLR 4 in conditions of ambient oxygen by examining the lungs of $\mathrm{Tlr}^{-/-}$mice in an unchallenged state. There were no differences between the lungs of WT and Tlr4-/- mice at 1 and 2 months of age, but by 3 months $\operatorname{Tlr}^{-/-}$mice showed significantly increased lung volumes (Figure 1A and Supplemental Figure 1; supplemental material available online with this article; doi:10.1172/JCI28139). Emphysema progressed and appeared to peak between 6 months and 1 year of age. There were no differences between the body weights of WT and $\mathrm{Tr}^{-4^{--}}$mice at 1, 3, 6, and 12 months of age. Histologic evaluation revealed enlargement of the air spaces distal to the terminal bronchioles accompanied by destruction of the normal alveolar architecture in $\mathrm{Tlr} 4^{-{ }^{-}}$mice, characteristic of emphysema (Figure 1B). Morphometric quantitation of the airspace enlargement revealed increased chord lengths in $\mathrm{Tlr}^{-/-}$mice (Figure 1C). Using 3 months of age as a representative time point, we confirmed our findings in different strains of TLR4-deficient mice, indicating that the observed phenotype was not strain dependent. C3H/HeJ, C57BL/10ScNJ, and C57BL/6J

\section{Figure 2}

Decreased EIC and increased elastin degradation in TIr4 $4^{-/-}$mice. (A) EIC was detected in BAL of 3-month-old WT and TIr4 $4^{--}$mice $(n=5-6)$. (B) Elastolytic activity was assayed in lung lysates of 3-month-old WT and TIr4 ${ }^{-/}$mice $(n=3)$. (C) Orcein staining for elastin in the elastic fibers of 3-month-old WT and TIr4-/- mice. (D) Immunohistochemistry using an antibody directed against elastin in the elastic fibers of 3-month-old WT and TIr4 ${ }^{-/-}$mice. Arrows indicate representative elastin staining in the fibers (brown-black). Original magnification, $\times 400$. Data are mean \pm SEM. ${ }^{*} P<0.05$ versus WT.

number of inflammatory cells isolated from bronchoalveolar lavage fluid (BAL) or from total lung digests of $\mathrm{Tlr}^{-/-}$and WT mice (Supplemental Figure 5). In addition, $\mathrm{Tlr} 4^{-/}$mouse lungs did not exhibit increased IL-1 $\beta$, TNF- $\alpha$, IL-6, VEGF, IL-13 and IFN- $\gamma$ mRNA or protein compared with WT lungs (Supplemental Figure 6). These data indicated that the etiology of emphysema in $\mathrm{Tlr} 4^{-/-}$mice could not be attributed to increased inflammation or cytokine and growth factor expression.
A

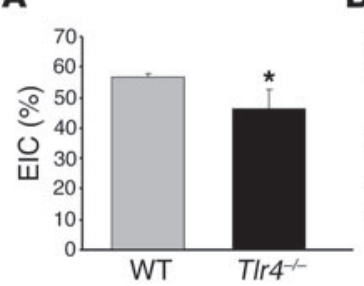

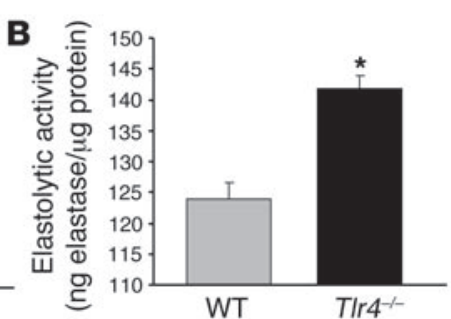

C

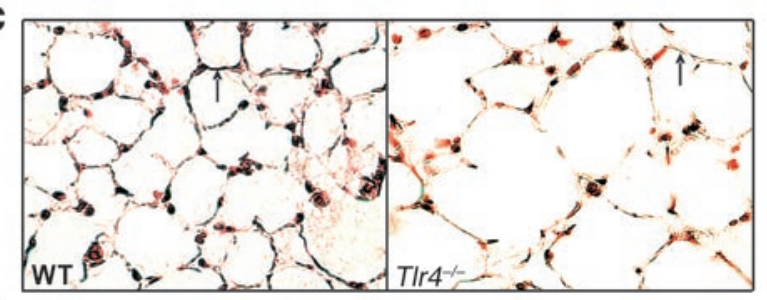

D

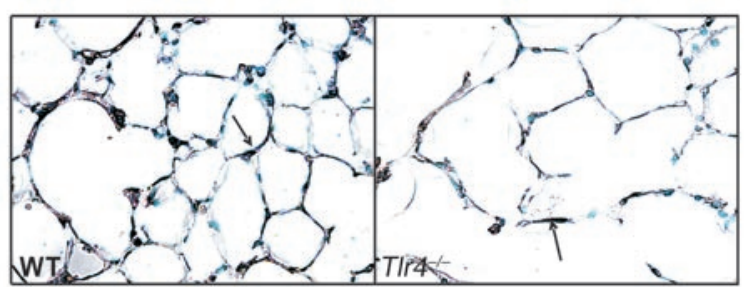


TLR4-deficient mice show decreased elastase inhibitory capacity. A protease/ antiprotease imbalance leading to the breakdown of lung elastin is thought to play a key role in the pathogenesis of pulmonary emphysema. Therefore, we quantitated antiprotease activity by measuring the elastase inhibitory activity in BAL and serum of $\mathrm{Tlr}^{-/-}$and WT mice. $T l r 4^{-/}$mice showed a marked decrease in their elastase inhibitory capacity (EIC) in BAL (Figure 2A), as well as in serum (data not shown), compared with WT mice. We also assayed for the presence of elastolytic activity in the lung lysates of $T l 4^{-/-}$mice and found markedly increased elastolytic activity compared with WT mice (Figure 2B). Similar results were also found in BAL (data not shown). We examined whether the decreased elastase inhibitory activity and increased elastolytic activity in the lungs of $\mathrm{Tlr}^{-/-}$mice led to the destruction of elastin-containing elastic fibers in the lung parenchyma with subsequent increase in lung compliance, a hallmark of human emphysema (18). Histochemical analyses for elastin in the elastic fibers as assessed by orcein and elastin staining showed thin, fragmented elastin segments in $\mathrm{Tlr}^{-/-}$mice, whereas the elastic fibers in WT mice appeared intact (Figure 2, C and D). Pulmonary function testing also revealed increased lung compliance in $\mathrm{Tlr}^{-/-}$mice compared with WT mice (Supplemental Figure 7). $\alpha 1$-AT is the prototypic member of the serine protease inhibitor (serpin) superfamily of proteins, which play a major role in inactivating neutrophil elastase and other proteases and thus maintaining the proteaseantiprotease balance in the lung (19). Therefore, we measured $\alpha 1-\mathrm{AT}$ concentrations in the serum and BAL of $\mathrm{Tlr}^{-/-}$and WT mice but found no differences (data not shown).

There is accumulating evidence for the role of MMPs and cathepsins in the pathogenesis of pulmonary emphysema $(17,20,21)$. Patients with COPD exhibit increased concentrations of MMP-9

\section{Figure 3}

Decreased antioxidant capacity and increased oxidant burden in $\mathrm{T} / \mathrm{r} 4^{-/-}$mice. (A) Total antioxidant activity was measured in the BAL of 3-month-old WT and TIr4 $4^{-/}$mice $(n=5-6)$. (B) The ratio of reduced GSH to oxidized GSH was detected in BAL of 3-month-old WT and TIr $4^{-/-}$mice $(n=6)$. (C) Quantitation of flow cytometric results from dihydroethidine staining in total lung cells isolated from 3-month-old WT and TIr4-/- mice $(n=3)$. MFI, mean fluorescence intensity. (D) Detection of $\mathrm{O}_{2}{ }^{-}$production by cytochrome $\mathrm{C}$ reduction assays in total lung cells isolated from 3-month-old WT and $\mathrm{TIr}^{-/-}$mice $(n=3)$. (E) Representative DNA oxidation detection by $8-\mathrm{OH}-\mathrm{dG}$ immunohistochemical staining in the lungs of 3-month-old WT and TIr4-/- mice. Arrow indicates positive red staining for $8-\mathrm{OH}-\mathrm{dG}$. Original magnification, $\times 400$. (F) Graphical quantitation of 8-OH-dG-positive cells expressed as \% of total cells in lung sections $(n=3)$. (G) Representative merged images of lung sections stained with TUNEL (green) and DAPI stain (blue) from 3-month-old WT and TIr4-- mice. Arrows indicate representative TUNELpositive cells (blue-green). Original magnification, ×200 (top panels); ×400 (bottom panels). (H) Graphical quantitation of TUNEL-positive cells expressed as percent of total cells in lung sections $(n=3)$. Data are mean \pm SEM. ${ }^{\star} P<0.05$ versus $\mathrm{WT}$.

(gelatinase B) and MMP-12 in BAL and sputum, respectively (22, 23). Animal models have shown that cigarette smoke-induced emphysema does not occur in mice lacking MMP-12 (8). However, when we examined the mRNA and protein levels of key MMPs, TIMPs, and cathepsins associated with the development of emphysema in $\mathrm{Tlr}^{-/-}$and WT mouse lungs, we found no significant differences (Supplemental Figures 8-10). Taken together, the lack of increased inflammatory cells, normal levels of the major lung antiprotease $\alpha 1-\mathrm{AT}$, and normal levels of key MMPs, TIMPs, and cathepsins in $\mathrm{Tlr}^{-/-}$mice indicated that TLR4 deficiency leads to increased lung elastolytic activity via alternative mechanisms.

TLR4-deficient mice show decreased antioxidant activity. Increased ROS, or oxidant stress, not only is important in the pathogenesis of emphysema but also can directly inactivate antiproteases (24). Therefore, we examined levels of oxidants in $T l r 4^{-/-}$mice by measuring the total antioxidant capacity in BAL and serum. The total antioxidant capacity was dramatically decreased in both the BAL (Figure 3A) and serum (data not shown) of $\mathrm{Tlr}^{-{ }^{--}}$mice compared with WT mice. Consistent with the reduced antioxidant capacity,

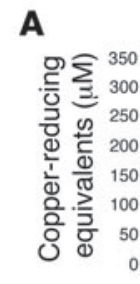

\section{C}
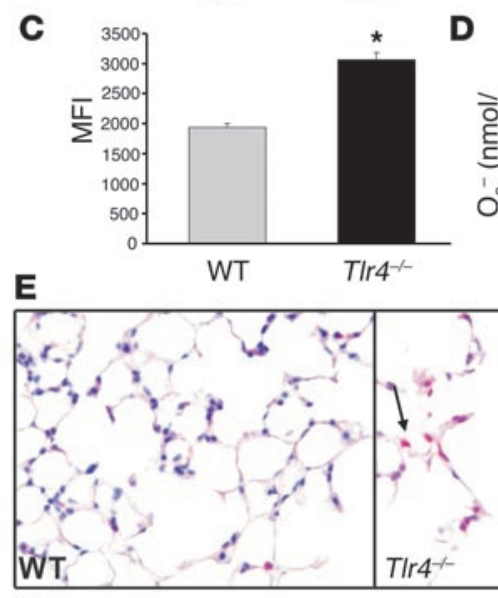

G
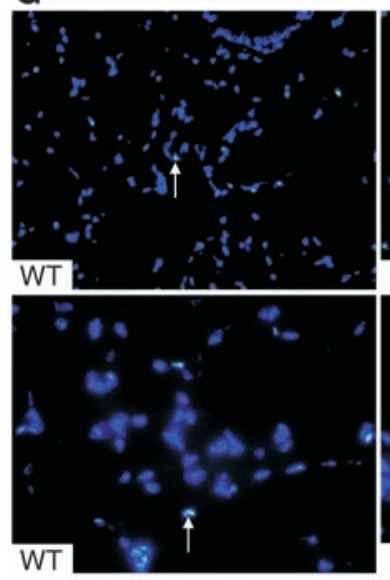
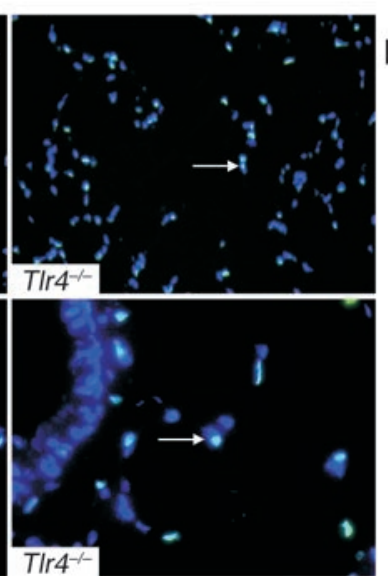

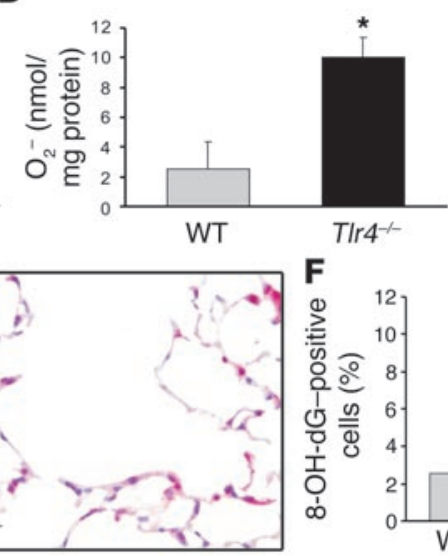

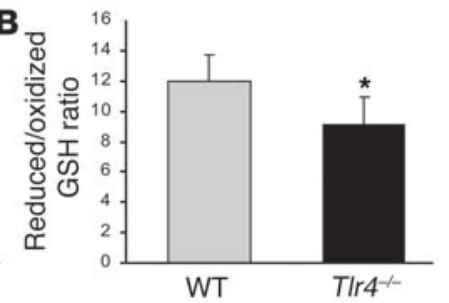

D

T/r4 ${ }^{-1-}$
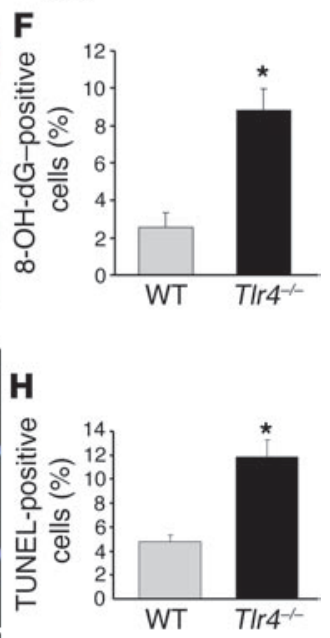

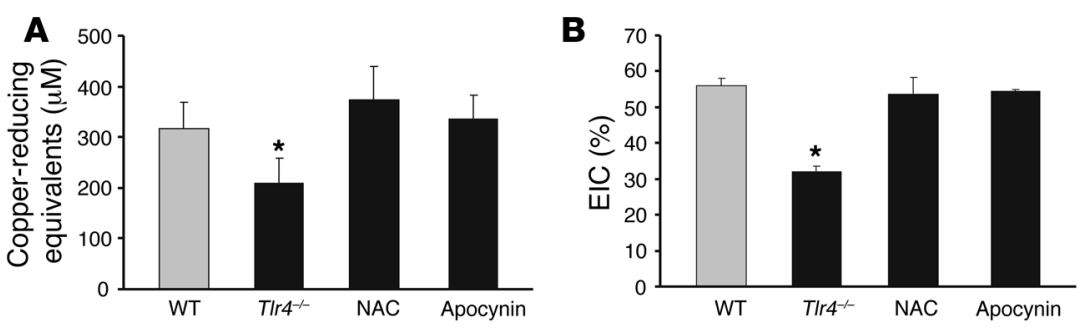

\section{Figure 4}

Antioxidant administration restores the antioxidant activity, EIC, and cell survival in TIr4-/- mice. TIr4-/mice were fed NAC, apocynin, or vehicle-only water and sacrificed at 3 months of age to determine total antioxidant activity in BAL (A); EIC in BAL (B); reduced $\mathrm{GSH}$ /oxidized GSH ratio in $\mathrm{BAL}(\mathbf{C})$; and TUNEL-positive cells (expressed as percent of total cells) in lung sections (D). ${ }^{*} P<0.05$ versus WT;
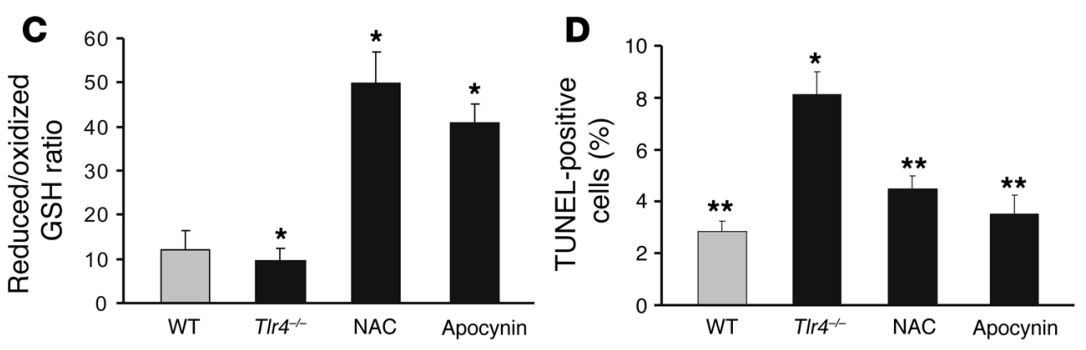

levels of reduced glutathione (GSH), the major antioxidant in the lung, were markedly decreased in BAL from $\mathrm{Tlr}^{-{ }^{-}-}$mice (Figure 3B). We have previously shown that Nox-dependent formation of the oxidant superoxide $\left(\mathrm{O}_{2}^{-}\right)$plays an important role in oxidant-induced lung injury (25). Therefore we investigated whether TLR4 deficiency in vivo leads to altered Nox-mediated $\mathrm{O}_{2}{ }^{-}$formation. Using fluorescence microscopy and flow cytometry detection for dihydroethidine, a measurement of $\mathrm{O}_{2}{ }^{-}$anion (26), we found marked increases of $\mathrm{O}_{2}^{-}$in isolated lung cells of $\mathrm{Tlr}^{-/-}$mice compared with WT mice (Figure 3C). We confirmed these Nox-mediated $\mathrm{O}_{2}{ }^{-}$measurements with a cytochrome $\mathrm{C}$ reduction assay (27). Again, the production of $\mathrm{O}_{2}^{-}$in isolated total lung cells from $\mathrm{Tlr}^{-{ }^{--}}$mice was significantly higher than that of WT mice (Figure 3D). These data suggested that $\mathrm{Tlr}^{-{ }^{-}}$mice accumulated exaggerated levels of the $\mathrm{ROS} \mathrm{O}_{2}^{-}$by 3 months of age via Nox-mediated mechanisms.

Targets of ROS include macromolecules such as lipids, proteins, and DNA, which become oxidized and lead to cellular dysfunction. Markers of lipid peroxidation have been found to be increased in patients with emphysema (28). Similarly, BAL from $\mathrm{Tlr}^{-{ }^{--}}$mice showed increased lipid oxidation, as assessed by malondialdehyde and 4-hydroxyalkenals production (data not shown). We also detected increased DNA oxidation in vivo, as measured by levels of 8-hydroxy-2'-deoxyguanosine (8-OH-dG), the oxidized form of guanine (Figure 3, E and F). Oxidants are key mediators of apoptosis, and lung apoptosis is thought to contribute to the development of emphysema in animal models and in humans $(29,30)$. Therefore, we evaluated $\operatorname{Tr} 4^{-/}$mice for DNA strand breaks in situ by fluorescent TUNEL staining and found an increased number of TUNEL-positive cells in the lungs of $\mathrm{Tlr}^{-/-}$mice compared with WT lungs (Figure 3, G and H). We confirmed our results using flow

\section{Figure 5}

Antioxidant administration ameliorates alveolar enlargement in $\mathrm{Tlr}^{-/-}$ mice, whereas adoptive transfer of WT bone marrow cells has no effect. (A) Lung volume. (B) Mean linear chord length. $n=4-5$. (C) Representative lung histology by H\&E. Original magnification, $\times 100$. (D) Lung volume was measured 2 months after adoptive transfer of bone marrow cells from WT mice to WT mice (WT $\rightarrow$ WT), TIr $4^{-/-}$mice

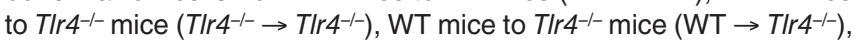
and $\mathrm{TIr}^{-/-}$mice to WT mice $\left(\mathrm{TIr}^{-/-} \rightarrow \mathrm{WT}\right)$. Data are mean \pm SEM. ${ }^{*} P<0.05$ versus WT or WT $\rightarrow$ WT; ${ }^{* *} P<0.05$ versus TIr $^{-1-}$. cytometric quantitation of TUNEL as well as annexin $\mathrm{V}$-propidium iodide (annexin V-PI) staining in isolated lung cells of $\mathrm{Tlr}^{-/-}$mice, which showed significantly increased lung cell death (Supplemental Figure 11). Next, we asked whether a caspase 3-mediated cell death was occurring in $\mathrm{Tlr} 4^{-/-}$mouse lungs and found that there were no differences in caspase 3 mRNA expression or levels of activated caspase 3 between WT and Tlr4-/- mice (Supplemental Figure 12). In addition, we did not find differences in caspase 8 or caspase 9 activation (data not shown). Thus far, our data indicate that
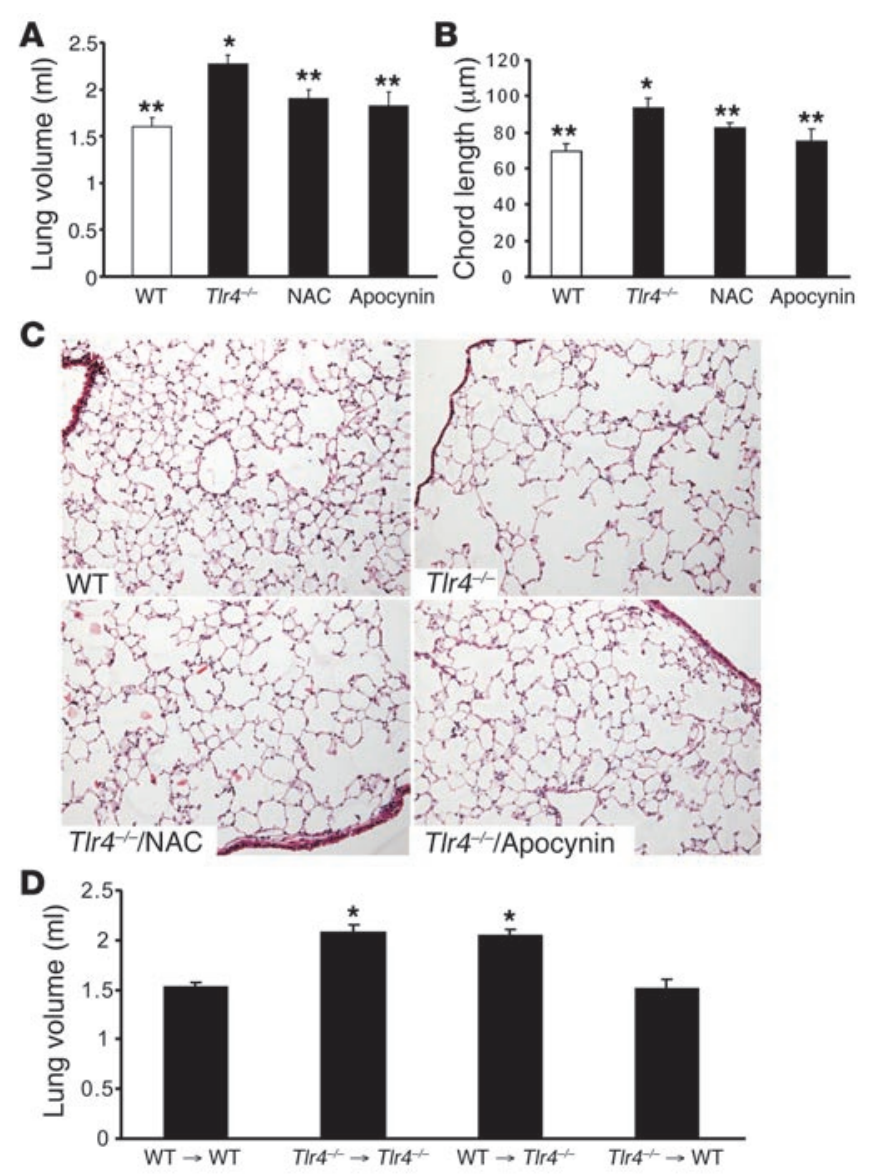

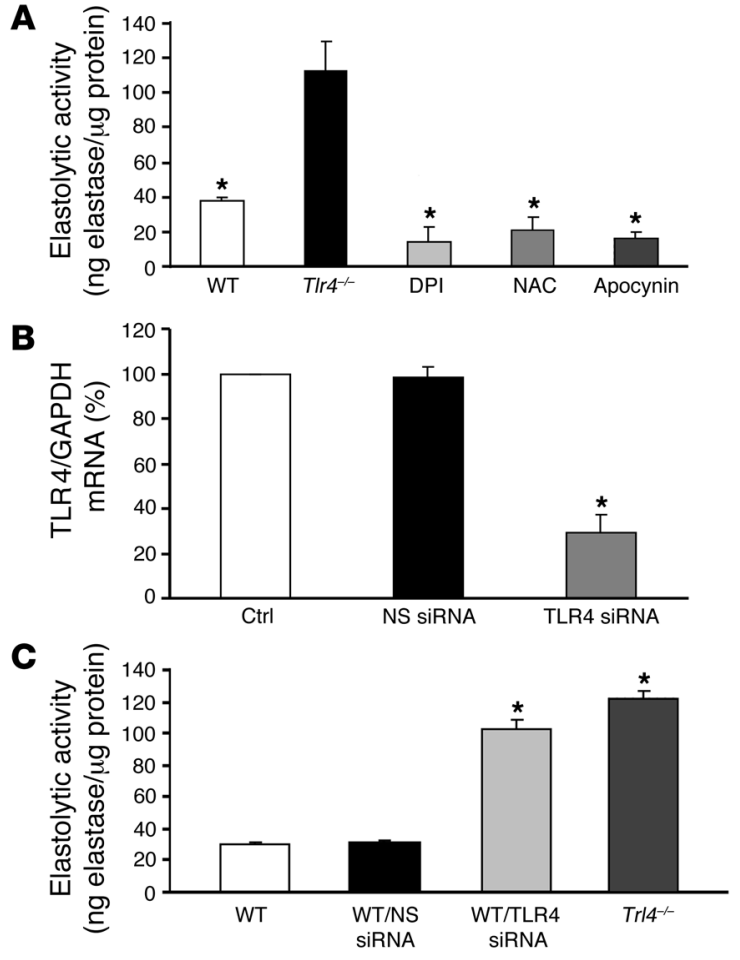

TLR4 deficiency leads to a prooxidant state and is associated with decreased antiprotease activity; increased elastin degradation, DNA oxidation, and cell death; and ultimately lung destruction.

Antioxidants reverse TLR4 deficiency-induced emphysema. To determine whether increased oxidants are responsible for the emphysema phenotype in $\mathrm{Tlr} 4^{-/-}$mice, we attempted to rescue the mice with antioxidant treatment. In addition to administering NAC, a GSH precursor, we also administered the Nox inhibitor apocynin because our data suggested a Nox-mediated mechanism of ROS generation in TLR4 deficiency. Both NAC and apocynin treatment increased the total antioxidant content in BAL (Figure 4A) and serum (data not shown) of Tlr4 ${ }^{-/-}$mice to the levels of WT mice. This was associated with an increase in the EIC and with increased GSH levels in $\mathrm{Tlr}^{-/-}$mice (Figure 4). Antioxidant therapy also decreased the number of lung TUNEL-positive cells (Figure 4D) and restored the antineutrophil elastase activity of $\alpha 1$-AT in $\mathrm{Tlr}^{-/-}$ mice (Supplemental Figure 13). Importantly, both NAC and apocynin treatment prevented TLR4-mediated emphysema (Figure 5, A-C). These data demonstrated a causal role for oxidants in the lung destruction observed in $T l r 4^{-/-}$mice.

TLR4 deficiency on lung parenchyma induces mouse lung emphysema. The contribution of cells from hematopoietic versus nonhematopoietic lineages in the pathogenesis of emphysema is unclear. Studies have shown that hematopoietic cell lineages, such as neutrophils, macrophages, and lymphocytes, play important roles in the pathogenesis of emphysema (31). However, studies have also shown that lung structural cells, such as endothelial and epithelial cells, are also involved in the pathogenesis of emphysema (32). We sought to examine the relative importance of TLR4 expression in these cell lineages by creating bone marrow-chimeric mice. Tlr4-/mice were transplanted with WT bone marrow, which would restore TLR4 expression in hematopoietic cells but not in lung structural cells, and conversely, WT mice were transplanted with TLR4-defi-

\section{Figure 6}

$T L R 4$ deficiency leads to increased Nox-mediated elastolytic activity in MLECs. (A) MLECs isolated from TIr4 ${ }^{-/}$mice were treated with DPI $(10 \mu \mathrm{M})$, NAC $(100 \mu \mathrm{M})$, or apocynin $(10 \mu \mathrm{M})$ for 24 hours, and elastolytic activity was assayed $(n=3)$. (B) TLR4 siRNA and nonspecific (NS) siRNA (80 nM) were transfected to WT MLECs, and TLR4 mRNA expression was analyzed by real-time RT-PCR $(n=3-5)$. Ctrl, untransfected control. (C) WT MLECs were transfected with nonspecific siRNA or TLR4 siRNA (80 nM), and elastolytic activity was assayed $(n=3)$. Data are mean \pm SEM. ${ }^{*} P<0.05$ versus $T / r 4^{-/-}(\mathbf{A})$, control and nonspecific siRNA (B), and WT and WT transfected with nonspecific siRNA (C).

cient bone marrow, which would result in TLR4 expression in lung structural cells but not in hematopoietic cells. We observed that WT bone marrow did not rescue $\mathrm{Tlr}^{-/-}$mice from emphysema and that Tlr $4^{-/-}$bone marrow did not induce emphysema in WT mice (Figure 5D). This indicates that TLR4 deficiency in nonhematopoietic cells (such as endothelial, epithelial, and fibroblast cells, which have been implicated in the pathogenesis of emphysema) is responsible for emphysema. We chose to focus upon lung endothelial cells for our subsequent studies because (a) endothelial cells account for the majority (46\%) of all lung cells (33); (b) endothelial cells are important in the pathogenesis of emphysema as well as in oxidant responses $(34,35)$; (c) endothelial cells have elastase-like activities (36-39); and (d) endothelial cells express TLR4 (40).

Nox regulates the increased elastolytic activity in $\mathrm{Tlr} 4^{-1-}$ lung endothelial cells. We first examined whether mouse lung endothelial cells (MLECs) isolated from $\mathrm{Tlr}^{-/-}$mice exhibit increased elastolytic activity. $\mathrm{Tlr}^{-/-}$MLECs showed markedly increased elastolytic activity compared with WT MLECs (Figure 6A). In order to confirm that the absence of TLR4 in endothelial cells leads to increased elastolytic activity, we used siRNA to knock down endogenous TLR4 expression (Figure 6B). MLECs transfected with TLR4 siRNA exhibited significantly increased elastolytic activity compared with WT MLECs and MLECs transfected with nonspecific siRNA (Figure 6C).

Although apocynin is widely used as a Nox inhibitor in vitro and in vivo $(41,42)$, we confirmed our data with a second Nox inhibitor, diphenylene iodonium (DPI) $(42,43)$. Consistent with our in vivo data using NAC and apocynin (Figure 4), we were able to reverse the elastolytic activity observed in $\mathrm{Tlr} 4^{-/-}$MLECs to levels achieved by the broad-acting antioxidant NAC using apocynin or DPI (Figure 6A). These data suggested that a Nox-mediated mechanism was responsible for the increased oxidants observed in Tlr4 $4^{-/-}$MLECs. Nox is a multimeric enzyme system of which Nox2 (gp91phox) is the most commonly described catalytic component, especially in phagocytic cells. Recently, several novel homologs of Nox2 have been described in a variety of nonphagocytic cells (Nox1-Nox5, Duox1, and Duox2; refs. 44, 45). Nox1 and Nox3 appear to be the closest structural homologs of Nox 2 , but the precise function and tissue distribution of these new Nox members are poorly defined. In order to determine whether TLR4 deficiency regulates Nox, we examined mRNA expression of various Nox proteins in lung lysates from $\mathrm{Tlr}^{-/-}$and WT mice. Nox3 was present at a very low level in WT lungs, whereas Tlr4-/- lung lysates showed increased expression of Nox3 mRNA and protein (Figure 7, A and B). Nox1, -2 , and -4 expression levels were similar between $\mathrm{Tlr}^{-/-}$and WT lungs (Supplemental Figure 14). Next, we examined Nox3 mRNA expression in MLECs and found that, similar to the lung lysates, 
A

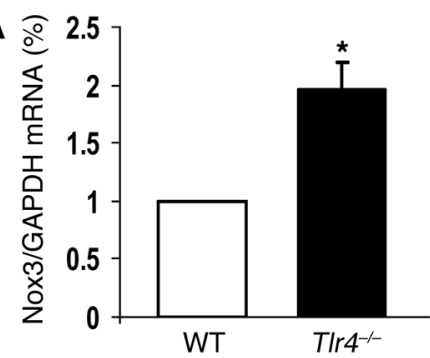

C

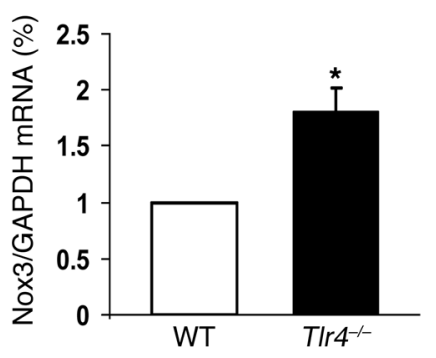

E

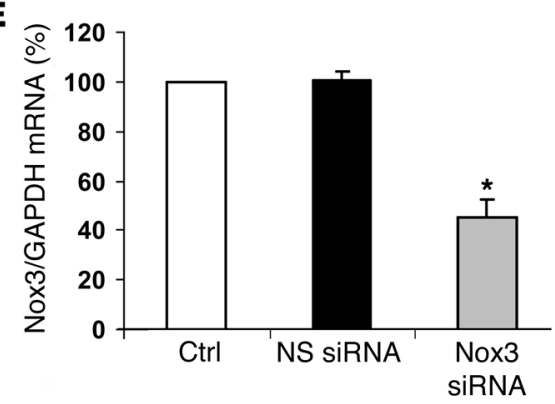

B
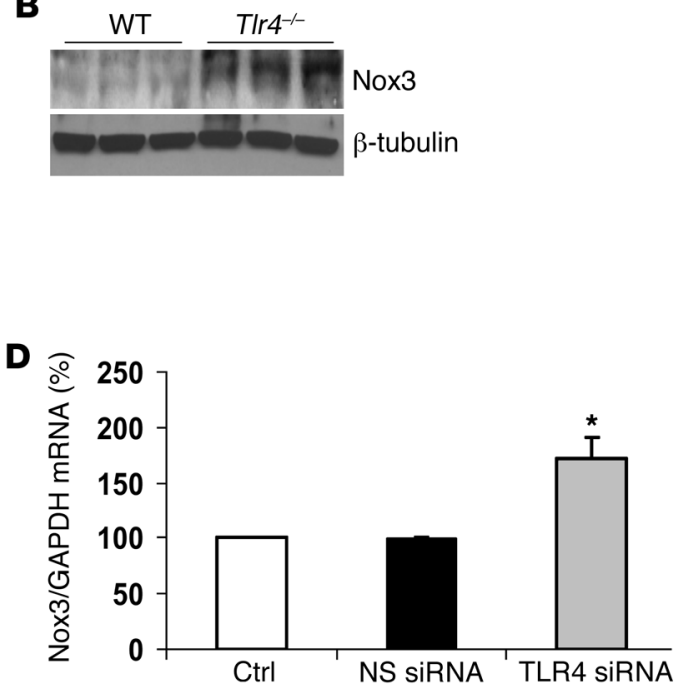

$\mathbf{F}$

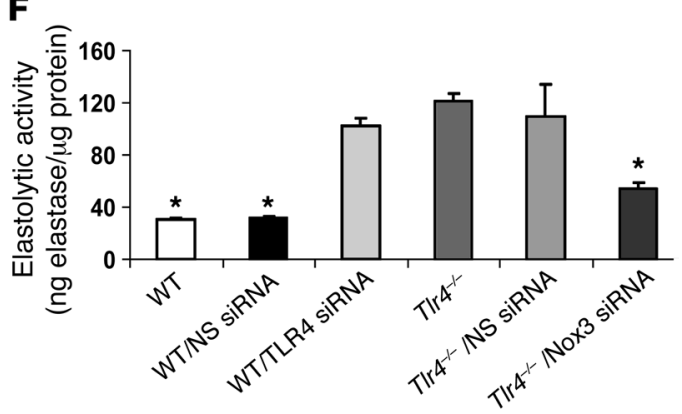

Figure 7

TLR4 deficiency leads to increased Nox3 expression in lung and lung endothelial cells. (A) Nox3 mRNA expression in 3-month-old WT and TIr4- ${ }^{-1-}$ mouse lungs as detected by real-time RT-PCR $(n=3)$. (B) Nox3 protein expression in 3-month-old WT and TIr $4^{-/-}$mouse lungs $(n=3)$. (C) Nox3 mRNA expression in MLECs isolated from WT and TIr4-/- mice as detected by real-time RT-PCR $(n=3)$. (D) Nox3 mRNA expression in WT MLECs transfected with nonspecific siRNA or TLR4 siRNA ( $80 \mathrm{nM}$ ) as detected by realtime RT-PCR compared with untransfected controls $(n=3)$. (E) Nox3 mRNA expression in WT MLECs transfected with nonspecific siRNA or Nox3 siRNA ( $80 \mathrm{nM})$ as detected by real time RT-PCR compared with untransfected controls $(n=3)$. (F) Elastolytic activity was detected in TIr4 $4^{-/}$MLECs transfected with Nox3 siRNA or nonspecific siRNA and WT MLECs transfected with TLR4 siRNA or nonspecific siRNA $(n=3)$. Data are shown as mean \pm SEM. ${ }^{*} P<0.05$ versus WT $(\mathbf{A}$ and $\mathbf{C})$, untransfected controls ( $\mathbf{D}$ and E), and $T / r 4^{-/-}(\mathbf{F})$.

Tlr4- $4^{--}$MLECs expressed increased Nox3 mRNA expression (Figure 7C). In order to confirm that the increased Nox3 expression is due to the absence of TLR4 in MLECs, we used TLR4 siRNA to knock down TLR4 expression in WT MLECs (Figure 6B). MLECs transfected with TLR4 siRNA expressed increased Nox3 mRNA compared with untreated control and nonspecific siRNA-treated MLECs (Figure 7D). We then examined whether TLR4 deficiencymediated Nox3 expression was responsible for increased elastolytic activity. We used Nox3 siRNA to knock down Nox3 expression in Tlr4 ${ }^{--}$MLECs (Figure 7E) and then examined levels of elastolytic activity. Nox3 siRNA significantly decreased the elastolytic activity observed in $\mathrm{Tlr}^{-/}$MLECs compared with untransfected or nonspecific siRNA-transfected MLECs (Figure 7F). As expected, MLECs transfected with TLR4 siRNA exhibited increased elastolytic activity to levels comparable to that of MLECs isolated from Tlr $4^{-/-}$mice (Figure 7F). These data indicated that TLR4 deficiency leads to increased Nox activity via the induction of Nox3 and, consequently, increased elastolytic activity in MLECs.

\section{Discussion}

Our findings demonstrate what we believe to be a previously unappreciated yet critical role for TLR4 in maintaining lung structural integrity by modulating oxidant generation. The gradual progression of emphysema in TLR4 mice is akin to the pace of emphysema that develops in humans. In combination with our recent reports that TLRs regulate hyperoxia- and bleomycin-induced lung injury (1-3), a new paradigm appears to be emerging in which TLR4 is essential for the ability of the lungs to tolerate injury-induced as well as ambient oxidant stresses. In the present study we demonstrate that TLR4 deficiency, specifically in lung endothelial cells, may contribute to the susceptibility to emphysema via novel oxidant mechanisms. Tlr $4^{-/-}$mice exhibited increased oxidant stress, elastin degradation, and lung cell death in the absence of overt lung inflammation.

There is considerable evidence that an increased oxidative burden occurs in the lungs of patients with emphysema, resulting in cell injury and/or death, mucus hypersecretion, antiprotease inactivation, and lung inflammation through activation of redox-sensitive transcription factors $(4,46)$. Interestingly, researchers have found that disruption of the $\mathrm{Nrf} 2$ gene, a transcriptional regulator of antioxidant enzymes, led to accelerated and more extensive cigarette smoke-induced emphysema in mice $(12,47)$. Furthermore, elastase-provoked emphysema was markedly exacerbated in Nrf2-deficient mice compared with WT mice (48). These studies highlight the importance of oxidant stress in the pathobiology of pulmonary emphysema. Of note, we did not detect differences in $\mathrm{Nrf2}$ expression in $\mathrm{Tlr}^{-/-}$mice. However, $\mathrm{Tlr} 4^{-/}$mice showed signs of increased oxidants, as assessed by levels of ROS, antioxidant capacity, and DNA oxidation. Furthermore, the significant reduction in pulmonary emphysema in $\mathrm{Tlr}_{4} 4^{-/}$mice treated with antioxidants indicated that oxidant stress is a pivotal mechanism for TLR4 deficiency to cause spontaneous emphysema.

Nox activity is a principal source of phagocytic oxidant generation, yet its role in nonphagocytic cells is only now emerging. Originally discovered in neutrophils, Nox generates millimolar quantities of $\mathrm{O}_{2}{ }^{-}$from molecular oxygen and plays a vital role in nonspecific host defense (49). Nox is assembled from a membranespanning flavocytochrome $b_{558}$, composed of Nox 2 , p22phox , and 4 cytosolic factors ( $\mathrm{p} 47^{\text {phox }}, \mathrm{p} 67^{\text {phox }}, \mathrm{p} 40^{\text {phox }}$, and Rac) that associate 
with the flavocytochrome to form an active enzyme. Recently, several novel homologs of Nox2 have been described in a variety of nonphagocytic cells $(44,45)$. This new Nox family encompasses 7 enzymes identified in humans: Nox1-Nox5, Duox1, and Duox2 (50). In neutrophils, Nox is normally dormant but is rapidly activated upon appropriate stimulation in a process involving the translocation and association of cytosolic subunits with the membrane-bound cytochrome $b_{558}$. Mutations in essential components of the oxidase lead to the condition of chronic granulomatous disease, which is characterized by recurrent life-threatening infections. It is becomingly increasingly evident that nonphagocytic cells such as fibroblasts, endothelial cells, vascular smooth muscle cells, and renal mesangial, tubular, and other cells also possess $\mathrm{O}_{2}^{-}$-producing enzymes analogous to phagocytic Nox (51-56). The nonphagocytic Noxs are structurally related to but functionally distinct from the widely studied neutrophil Noxs and have the ability to generate constitutive levels of $\mathrm{O}_{2}^{-}$even in unstimulated conditions.

In our present study, we showed that endogenous Nox activity, specifically that of Nox3, was upregulated in $\mathrm{Tlr} 4^{-/-}$mice, leading to increased oxidant generation and elastolytic activity. The increased Nox activity was responsible for the increased elastolytic activity, as when Nox was inhibited by DPI, apocynin, or Nox3 siRNA, the elastolytic activity was significantly decreased in vivo and in vitro. Nox3 mRNA has been detected by RT-PCR in fetal kidney, liver, lung, and spleen (57). Recently, a role for this oxidase was reported within the inner ear (vestibular system): Nox3derived oxidants were implicated as having a role in hearing loss and balance problems $(58,59)$. Our studies are the first to our knowledge to show a role for Nox3 in regulating the lung oxidant environment and to identify lung endothelial cells as a source of Nox3-mediated elastolytic activity. We propose that TLR4 acts as a tonic suppressor of endogenous Nox3 activity in the lung, allowing tight regulation of the oxidant milieu.

Excessive protease activity will lead to the breakdown of connective tissue components, particularly elastin (60). Degradation of elastin, the principal component of elastic fibers, results in the loss of the lung parenchyma and the emphysema phenotype. There is substantial evidence that the number of neutrophils and macrophages is increased in the airspaces in chronic smokers. Animal studies also showed that neutrophil elastase contributes to cigarette smoke-induced emphysema in mice (61). In the present study, the EICs in BAL and serum were significantly lower in $T l r 4^{-/-}$mice than in WT mice, likely due to oxidant-mediated inactivation of $\alpha 1$-AT, which caused a reduced capacity to inhibit pancreatic elastase. In accord with these findings, $\mathrm{Tl} r 4^{-/-}$mice also exhibited significantly higher elastolytic activity compared with WT mice. However, the lack of prominent lung inflammation in the $T l r 4^{-/}$mice and the importance of structural cell TLR4 in maintaining lung integrity, as evidenced by our chimeric bone marrow transplantation data, indicated to us that inflammatory cells are not the primary source of increased protease activity. Notably, we did not detect differences in other proteases and antiproteases implicated in the pathogenesis of emphysema, such as the MMPs, the TIMPs, $\alpha 1-\mathrm{AT}$, and several cathepsins. Therefore, we speculate that a novel protease is responsible for the elastin degradation observed in Tlr4 $4^{-/}$lungs; this will become the focus of intense future investigations.

We identified lung endothelial cells as a source of the increased oxidant generation and protease activity in $\mathrm{Tlr}^{-/-}$mice. Endothelial cells have been found to possess elastase-like activity (36-39). In addition, Platt et al. used fluorescently labeled gelatin and elastin as matrix substrates to demonstrate that live endothelial cells exhibit varying degrees of gelatinase and elastase activities depending upon the degree of shear stress (62). We found that TLR4-deficient endothelial cells and WT lung endothelial cells, in which TLR4 expression was silenced, exhibited exaggerated levels of elastolytic activity that was reversed in the presence of Nox3 siRNA. These findings support an emerging role for the endothelium as a dynamic and important determinant of the oxidant environment in the lung and may play a key systemic role as well.

In conclusion, we show that disruption of the TLR4 pathway contributes to the susceptibility of emphysema. Particles in the ambient air contain LPS, the prototypic ligand for TLR4, at subnanogram levels (63). Chronic instillation of LPS $(500 \mu \mathrm{g})$ has been shown to cause emphysema $(64,65)$. This is likely a function of the high doses used with subsequent activation of different cellular pathways, analogous to the differential inflammatory responses evoked by high and low levels of inhaled LPS (66). Our studies clearly demonstrate that TLR4 is required for lung homeostasis under normal conditions, akin to the requirement for TLRs in the gut under basal conditions (67). We have identified TLR4 as a critical host factor that protects against oxidative stress by regulating Nox activity and thereby preserving tissue integrity. These studies expand our understanding of the molecular mechanisms required to maintain the critical oxidant/antioxidant balance in the unchallenged lung and establish what we believe to be novel links between innate immunity and oxidant stress.

\section{Methods}

Animals. Tlr4-/- and $\mathrm{MyD} 88^{-/-}$mice (originally provided by S. Akira, Osaka University, Osaka, Japan) have been previously described (1, 68, 69). TLR4deficient mouse lines $\mathrm{C} 3 \mathrm{H} / \mathrm{HeJ}$ and $\mathrm{C} 57 \mathrm{BL} / 10 \mathrm{ScNJ}$ and their respective controls were purchased from The Jackson Laboratory. C57BL/6J Tlr4-/mice were generated after greater than 10 generations of backcrossing onto a C57BL/6J background. WT littermates were used as controls. For antioxidant therapy, $\mathrm{Tlr}^{-/-}$mice were randomized into 3 groups at 3 weeks of age - NAC ( $1 \mathrm{~g} / \mathrm{kg}$ body weight; Sigma-Aldrich) (70), apocynin ( $3 \mathrm{mg} / \mathrm{kg}$ body weight; Calbiochem; EMD Biosciences) (71), or vehicle-only drinking water - and then sacrificed at 3 months. Mice were maintained under specific pathogen-free conditions at the animal facility of Yale University School of Medicine. Animal protocols were reviewed and approved by the Animal Care and Use Committee at Yale University.

Irradiation and bone marrow transplantation. Whole-body irradiation of recipient mice and harvesting of donor bone marrow was performed as described previously (72). Briefly, donor bone marrow was flushed from the femurs, tibias, and humeri of 6- to 8-week-old mice with cold sterile PBS. The cell suspension was repetitively aspirated until no visible fragments remained. Cells were pelleted at $300 \mathrm{~g}$ for 10 minutes at $4^{\circ} \mathrm{C}$ before counting. Recipient mice at 3 weeks of age underwent whole-body irradiation (1,000 cGy) followed by intravenous injection of whole bone marrow cells $\left(9 \times 10^{6}\right.$ cells in $0.2 \mathrm{ml}$ PBS). After bone marrow transplantation, mice were maintained until 3 months of age under specific pathogen-free conditions at the Yale University School of Medicine animal facility and fed acidic water.

Histology. Animals were anesthetized, the pulmonary intravascular space was cleared, and lungs sections were processed for $\mathrm{H} \& \mathrm{E}$, orcein, TUNEL, and 8-OH-dG staining as described previously (1). Immunohistochemistry was also applied to stain the elastin in the lungs. Briefly, formalin-fixed, paraffinembedded lung tissue sections were deparaffinized with xylene, rehydrated gradually with graded alcohol solutions, and then washed with deionized water. Sections were incubated with a 1:200 dilution of anti-elastin monoclonal antibody (Chemicon International) at $37^{\circ} \mathrm{C}$ for 2 hours. After PBS washes, 
sections were incubated with a 1:200 dilution of biotinylated anti-mouse IgG at $37^{\circ} \mathrm{C}$ for 60 minutes, and peroxidase-conjugated streptavidin-biotin complex was incubated at $37^{\circ} \mathrm{C}$ for 60 minutes. After further washing the sections with PBS, we applied 3,3'-diaminobenzidine tetrachloride/nickel-cobalt substrate as the chromogen, yielding a brown-black-colored reaction product, and counterstained the sections with methyl green (Vector Laboratories).

Lung volume, morphometric assessment, and compliance assessment. Lung volume, lung compliance, and alveolar size were assessed via volume displacement and morphometric chord length assessments as previously described (73).

Total lung cell and inflammatory cell isolation. For total lung cell isolation, mice were anesthetized, and the pulmonary vasculature was perfused with PBS until free of blood. The lungs were filled with 1-2 $\mathrm{ml}$ of dispase II (Roche Diagnostics) and then placed into a conical tube containing $2 \mathrm{ml}$ of dispase II solution at room temperature for 45 minutes. The lungs were then transferred to a petri dish containing PBS with $50 \mathrm{U} / \mathrm{ml}$ DNase I (Sigma-Aldrich), 5\% FBS, and $1 \mathrm{mg} / \mathrm{ml}$ collagenase A (Roche Diagnostics). After separating the digested tissue, lungs were incubated for 60 minutes at $37^{\circ} \mathrm{C}$, and the resulting cell suspensions were filtered through $100-\mu \mathrm{m}$ cell strainers (BD Falcon; BD Biosciences). The total lung inflammatory cell isolation has been described previously (72).

Isolation of primary MLECs. MLECs were isolated by as described by Kuhlencordt et al. (74), with some modifications. Briefly, lungs were extracted, minced, and digested for 1 hour at $37^{\circ} \mathrm{C}$ with $0.1 \%$ collagenase (Roche Diagnostics) in RPMI-1640 with $100 \mathrm{U} / \mathrm{ml}$ penicillin $\mathrm{G}$ and $100 \mu \mathrm{g} / \mathrm{ml}$ streptomy$\mathrm{cin}$. The digest was passed through a $100-\mu \mathrm{m}$ cell strainer to remove undigested tissue fragments. Cells were pelleted at $200 \mathrm{~g}$ for 5 minutes; resuspended in MLEC medium containing 20\% FBS, 40\% DMEM, and 40\% F12 with 100 $\mathrm{U} / \mathrm{ml}$ penicillin $\mathrm{G}$ and $100 \mu \mathrm{g} / \mathrm{ml}$ streptomycin; and plated onto $0.1 \%$ gelatin-coated T75 flasks. Cells were washed after 24 hours and cultured for 2-4 days. Cells were trypsinized with $2 \mathrm{ml}$ trypsin/EDTA, PBS added, and spun for 5 minutes at $200 \mathrm{~g}$ to remove the supernatant. Cells were resuspended in $2 \%$ FBS containing $10 \mu \mathrm{l}$ biotin-labeled rat anti-mouse CD31 (PECAM-1) antibody (BD Biosciences - Pharmingen). After incubation on ice for $30 \mathrm{~min}$ utes, the cells were washed with streptavidin magnetic beads (New England Biolabs Inc.). Cells were washed with $2 \% \mathrm{FBS}$, resuspended in $5 \mathrm{ml}$ of $2 \% \mathrm{FBS}$, and incubated on ice for 30 minutes. The cells were then placed on the magnet for 5 minutes, and unbound cells were removed while bound cells were resuspended in medium and plated onto a $0.1 \%$ gelatin-coated T25 flask. We confirmed with CD31 staining and flow cytometry that greater than $95 \%$ of the cells were endothelial cells. Cells were maintained in 40\% DMEM and $40 \%$ F12 tissue culture medium supplemented with $20 \%$ FBS.

Flow cytometric analysis for TUNEL and annexin V-PI staining in lung cells. Total lung cells of $\mathrm{Tlr}^{-/-}$and WT mice were resuspended in PBS and adjusted to $2 \times 10^{7}$ cells $/ \mathrm{ml}$. After fixation with $2 \%$ paraformaldehyde and permeabilization with $0.1 \%$ Triton $\mathrm{X}-100$, the lung cells were incubated with TUNEL reaction mixture for 60 minutes. Negative control was incubated with TUNEL reaction buffer without terminal deoxynucleotidyl transferase. Cells were washed twice with PBS, and TUNEL staining was detected by flow cytometry (BD) and then analyzed using CellQuest FACSConvert software (version 7.5.3; BD). For annexin V-PI staining, $1 \times 10^{6}$ cells were resuspended in $1 \times$ binding buffer $(10 \mathrm{mM}$ HEPES/NaOH, pH 7.4; $140 \mathrm{mM}$ $\mathrm{NaCl}$; and $2.5 \mathrm{mM} \mathrm{CaCl}_{2}$ ), $5 \mu \mathrm{l}$ annexin $\mathrm{V}$ and $5 \mu \mathrm{l}$ PI were added, and cells were incubated for 15 minutes in the dark. Binding buffer $(400 \mu \mathrm{l})$ was then added to each tube and analyzed by flow cytometry (BD).

Western blot analysis. Protein was extracted from cell or lung tissue lysates, electrotransferred, and then immunoblotted with rabbit MMP-9 (Chemicon International), rabbit MMP-2 and MMP-13 (Santa Cruz Biotechnology Inc.), or goat cathepsin B, S, or H or Nox3 (Santa Cruz Biotechnology Inc.) antibodies. Detection was performed with Phototope-HRP Western Blot Detection System (Cell Signaling Technology). Equivalent sample loading was confirmed by stripping membranes with Blot Restore Membrane rejuvenation solution (Chemicon International) and reprobing with anti- $\beta$-tubulin antibody (Santa Cruz Biotechnology Inc.).

Caspase 3 expression by flow cytometry. Cells were centrifuged and fixed with $2 \%$ formaldehyde for 10 minutes at $37^{\circ} \mathrm{C}$. Tubes were chilled on ice for 1 minute, and cells were permeabilized by adding ice-cold $100 \%$ methanol slowly, while gently vortexing, so that the final concentration was $90 \%$ methanol. After incubation on ice for 30 minutes, cells were counted using a hemacytometer, and $1 \times 10^{6}$ cells were aliquoted into each assay tube. Incubation buffer $(0.5 \%$ BSA in $1 \times$ PBS; $2 \mathrm{ml})$ was added to each tube and rinsed by centrifugation. Cells were resuspended in $100 \mu$ incubation buffer per assay tube and allowed to sit at room temperature for 10 minutes. Cleaved caspase 3 rabbit monoclonal antibody was added to the assay tubes at 1:100 dilution and incubated for 60 minutes at room temperature. Cells were rinsed in incubation buffer by centrifugation, resuspended in Alexa Fluor $555 \mathrm{~F}\left(\mathrm{ab}^{\prime}\right) 2$ fragment of goat anti-rabbit $\operatorname{IgG}(\mathrm{H}+\mathrm{L})$ antibody (1:1,000 dilution), and incubated for 30 minutes at room temperature. After an additional rinse in incubation buffer by centrifugation, the cells were resuspended in $0.5 \mathrm{ml}$ PBS and analyzed by flow cytometry (BD).

Preparation of siRNA and transfection of siRNA duplexes. Nox3 and TLR4 siRNA was purchased from Santa Cruz Biotechnology Inc. Nonspecific siRNA scrambled duplex probes (sense, 5'-GCGCGCUUUGUAGGAUUCG-3'; antisense, 5'-CGAAUCCUACAAAGCGCGC-3') were synthesized by Dharmacon Research Inc. as previously described (75). MLECs were seeded onto 6-well plates 1 day prior to transfection using 40\% DMEM and 40\% F12 tissue culture medium supplemented with $20 \% \mathrm{FBS}$, without antibiotics. At the time of transfection with the specific siRNA, the cells were 50\%-60\% confluent. Oligofectamine Reagent (Invitrogen) was used as the transfection agent, and cells were then incubated for 6 hours, after which FBS was added to reach a final concentration of $20 \%$ FBS in the wells. After 48 hours' incubation, the cells were collected and subjected to the assays described below.

$R N A$ extraction and $m R N A$ analyses. Total RNA from lung tissue was extracted using TRIzOL reagent (Invitrogen) according to the manufacturer's instructions. The following primers were used in RT-PCR: mouse caspase $3,5^{\prime}$-TGTCATCTCGCTCTGGTACG-3' ${ }^{\prime}$ and $5^{\prime}$-TAACGCGAGTGAGAATGTGC-3'; Nox3, 5'-GCCTACGGGATAGCTGTCAA- ${ }^{\prime}$ and $5^{\prime}$-GGACTGCAGATGGGTGACTC-3'; $\beta$-actin, $5^{\prime}$-GTGGGCCGCTCTAGGCACCAA-3' and $5^{\prime}$-CTCTTTGATGTCACGCACGATTTC- $3^{\prime}$. Primers for MMPs, cathepsins, and TIMPs were described previously (16). RT-PCR was performed using RT-PCR Master Mix (USB). Conditions for RT-PCR were as follows: 1 cycle at $42^{\circ} \mathrm{C}$ for 30 minutes; 1 cycle at $95^{\circ} \mathrm{C}$ for 3 minutes; 30 cycles at $95^{\circ} \mathrm{C}$ for 30 seconds, $60^{\circ} \mathrm{C}$ for 1 minute, and $68^{\circ} \mathrm{C}$ for 90 seconds; and 1 cycle at $68^{\circ} \mathrm{C}$ for 5 minutes. Each reaction product $(10 \mu \mathrm{l})$ was then separated on a $1 \%$ agarose gel containing $0.5 \mu \mathrm{g} / \mathrm{ml}$ ethidium bromide. Real-time RT-PCR was performed using a QuantiTect SYBR Green RT-PCR kit (QIAGEN) according to the manufacturer's instructions. Reactions were made by a combination of $12.5 \mu \mathrm{l}$ SYBR RT-PCR Master Mix (QIAGEN), $0.25 \mu \mathrm{l}$ QuantiTect RT Mix (QIAGEN), $1 \mu \mathrm{l}$ upstream primer, $1 \mu \mathrm{l}$ downstream primer, $8.75 \mu \mathrm{l}$ RNase-free water, and $1.5 \mu \mathrm{l}(200 \mathrm{ng} / \mu \mathrm{l})$ RNA template. A negative control containing no RNA template was introduced in each run. Mouse Gapdh gene was amplified as an internal control. RT-PCR was performed using ABI Sequence Detection System (Applied Biosystems), in which the mixture was heated to $50^{\circ} \mathrm{C}$ for $30 \mathrm{~min}$ utes for reverse transcription and $95^{\circ} \mathrm{C}$ for 15 minutes, then cycled 40 times at $94^{\circ} \mathrm{C}$ for 15 seconds, $60^{\circ} \mathrm{C}$ for 30 seconds, and $72^{\circ} \mathrm{C}$ for 30 seconds. The primers used were as follows: cathepsin B, $5^{\prime}$-GCAGGACTTCCAAAAGAACGA-3' and 5'-GACGAATGCCTGCCACAAG-3'; cathepsin S, 5'-GAGACCCTACCCTGGACTACCA-3' and 5'-CCCAGATGAGACGCCGTACT-3'; cathepsin D, 5'-CCCCTCCATTCATTGCAAGAT-3' and 5'-CAAAGGACGTGCCGTTCTTC-3'; cathepsin H, 5'-GATTGTGCCCAAGCCTTCAA$3^{\prime}$ and $5^{\prime}$-CTGTCTTCTTCCATGATGCCC-3'; MMP-12, 5'-CATTTC- 
GCCTCTCTGCTGATG-3' and 5'-TTGATGGTGGACTGCTAGGTTTT-3'; MMP-2, 5'-AGATGCTGCCTTTAACTGGAGTAAG-3' and 5'-CCCGGGTCCATTTTCTTCTT-3'; MMP-9, 5'-CCCTGGAACTCACACGACA-3' and 5'-GGAAACTCACACGCCAGAAG-3'; MMP-13, 5'-TCCCTGGAATTGGCAACAAAG-3' and 5'-GGAATTTGTTGGCATGACTCTCAC-3'; MMP-14, 5'-AAGGCTGATTTGGCAACCAT-3' and 5'-AGCGCTTCCTCCGAACATT-3'; Nox1, 5'-CCTTCCATAAGCTGGTGGCA-3' and 5'GGCCTGTTGGCTTCTTCTGTAG-3'; Nox2, 5'-CTTATCACAGCCACAAGCATTGAA-3' and 5'-CACCCATTCACACTGACCTCTG-3'; Nox3, $5^{\prime}$-CTCGTTGCCTACGGGATAGC-3' and 5'-CCTTCAGCATCCTTGGCCT3'; Nox4, 5'-ACAACCAAGGGCCAGAATACTACTAC-3' and 5'-GGATGAGGCTGCAGTTGAGG-3'; TLR4, 5' -TCTGATCATGGCACTGTTCTTCTC-3' and $5^{\prime}$-GGGATTCAAGCTTCCTGGTGT-3'; IL-1 $\beta$, 5' ${ }^{\prime}$-CTGAACTCAACTGTGAAATGCCA-3' and 5'-AAAGGTTTGGAAGCAGCCCT-3'; TNF- $\alpha$, 5'-AGTTCCCAAATGGCCTCCC-3' and 5'-GCTACGACGTGGGCTACAGG3'; IL-6, 5'-AGAAAACAATCTGAAACTTCCAGAGAT-3' and 5'-GAAGACCAGAGGAAATTTTCAATAGG-3'). The relative quantification values for these gene expressions were calculated from the accurate threshold cycle $\left(C_{T}\right)$, which is the PCR cycle at which an increase in reporter fluorescence from SYBR green dye can first be detected above a baseline signal. The $C_{T}$ values for GAPDH were subtracted from the $C_{T}$ values for MMP- $2,-9,-12,-13$, and -14 ; cathepsin B, S, D, and $\mathrm{H}$; and TLR4 in each well to calculate $\Delta \mathrm{C}_{\mathrm{T}}$. The triplicate $\Delta \mathrm{C}_{\mathrm{T}}$ values for each sample were averaged. To calculate the fold induction of MMPs, cathepsins, Noxs, TLR4, IL-1 $\beta$, TNF- $\alpha$, and IL- 6 mRNA over controls $\left(\Delta \Delta C_{T}\right)$, the average $\Delta C_{T}$ values calculated for WT animals were subtracted from $\Delta \mathrm{C}_{\mathrm{T}}$ values calculated for $T l r 4^{-/}$animals. Next, the fold induction for each well was calculated using the $2^{-\left(\Delta \Delta \mathrm{C}_{\mathrm{T}}\right)}$ formula (73). The fold induction values for triplicate wells were averaged, and data were presented as the mean \pm SEM of triplicate wells.

Elastolytic activity. The elastolytic activities in lung tissues, BAL, and cell lysates was determined by hydrolysis of insoluble elastin and detected spectrophotometrically using elastin-Congo red as a substrate according to the method described previously (76). Briefly, elastin-Congo red (Sigma-Aldrich) was suspended in $0.1 \mathrm{M}$ Tris- $\mathrm{HCl}$ buffer $(\mathrm{pH}$ 7.4) at a concentration of $10 \mathrm{mg} / \mathrm{ml}$. A total $200 \mu \mathrm{l}$ of reaction mixture consisted of elastin-Congo red suspension (final concentration, $5 \mathrm{mg} / \mathrm{ml}$ ), varying concentrations of porcine elastase (Sigma-Aldrich) to generate a standard curve, and varying amounts of the sample of interest diluted in the same buffer. The mixture was incubated for 24 hours at $37^{\circ} \mathrm{C}$, and the reaction mixture was filtered with a $40-\mu \mathrm{m}$ mesh and then centrifuged for 5 minutes at $850 \mathrm{~g}$ at room temperature. The optical density of the supernatant was measured at $485 \mathrm{~nm}$ with a DYNEX Revelation version 3.2 spectrophotometer. The elastolytic activity was calculated as ng elastase/ $\mu \mathrm{g}$ protein in the lysates according to the standard curve established by the reaction of porcine elastase and elastin-Congo red.

Assessment of antiprotease activity. EIC was assessed in BAL and serum using previously described methods $(77,78)$. Briefly, BAL and serum were tested for EIC against porcine pancreatic elastase (PPE). EICs against PPE (type III; Sigma-Aldrich) in BAL and serum were determined using succinyl-trialanine-p-nitroanilide (SAPNA; Sigma-Aldrich) as the elastase substrate. EIC was expressed as percentage of enzyme activity inhibited by serum or BAL samples. Serum or BAL samples were incubated with PPE at room temperature for 20 minutes before adding the substrate SAPNA. Substrate hydrolysis was checked spectrophotometrically for 3 minutes at $410 \mathrm{~nm}$. The percentage of inhibition was calculated as follows: [(uninhibited rate - inhibited rate)/uninhibited rate] $\times 100$, where the uninhibited rate reflects the rate at which the PPE degrades its substrate, SAPNA, and the inhibited rate reflects the rate at which the PPE degrades SAPNA in the presence of serum or BAL.

Total antioxidant capacity. Total antioxidant capacity was measured in cellfree BAL and serum using the Quantitative Assay for Total Antioxidant Potential kit (Oxis International Inc.) according to the manufacturer's instructions. Briefly, equal amounts of BAL or serum were incubated with Bathocuproine (2,9-dimethyl-4,7-diphenyl-1,10-phenanthroline) and $\mathrm{Cu}^{2+}$ containing reagents. Bathocuproine selectively forms a 2:1 complex with $\mathrm{Cu}^{+}$, which has a maximum absorbance at $490 \mathrm{~nm}$. A standard of a known uric acid concentration was used to create a calibration curve. Results are expressed as $\mu \mathrm{M}$ copper-reducing equivalents.

Reduced and oxidized GSH content. The ratio of reduced GSH to oxidized GSH was measured in cell-free BAL using GSH/GSSG-412 kit (Oxis International Inc.) according to the manufacturer's instructions.

Lipid peroxidation. Malondialdehyde and 4-hydroxyalkenals were measured using Lipid Peroxidation Assay kit (Calbiochem; EMD Biosciences) according to the manufacturer's instructions.

Quantification of IL-13, IFN- $\gamma$, and VEGF in BAL. The levels of IL-13, IFN- $\gamma$, and VEGF protein in BAL were quantitated using commercial ELISA kits (R\&D Systems) according to the manufacturer's instructions and as described previously (73).

Statistics. Data are expressed as mean \pm SEM and were analyzed by 2 -tailed Student's $t$ test. $P$ values less than 0.05 were considered to be significant.

\section{Acknowledgments}

We thank Susan Ardito for her administrative and editorial assistance. Patty J. Lee is supported by NIH grant RO1 HL071595, an American Heart Association Heritage Affiliate Grant, and an American Lung Association Career Investigator Award.

Received for publication February 6, 2006, and accepted in revised form September 12, 2006.

Address correspondence to: Patty J. Lee, Section of Pulmonary and Critical Care Medicine, Yale University School of Medicine, P.O. Box 208057, New Haven, Connecticut 06520-8057, USA. Phone: (203) 785-5877; Fax: (203) 785-3826; E-mail: patty.lee@yale.edu.
1. Zhang, X., et al. 2005. Cutting edge: TLR4 deficiency confers susceptibility to lethal oxidant lung injury. J. Immunol. 175:4834-4838.

2. Qureshi, S.T., et al. 2006. Inducible activation of TLR4 confers resistance to hyperoxia-induced pulmonary apoptosis. J. Immunol. 176:4950-4958.

3. Jiang, D., et al. 2005. Regulation of lung injury and repair by Toll-like receptors and hyaluronan. Nat. Med. 11:1173-1179.

4. MacNee, W. 2005. Pulmonary and systemic oxidant/antioxidant imbalance in chronic obstructive pulmonary disease. Proc. Am. Thorac. Soc. 2:50-60.

5. Rennard, S.I., and Vestbo, J. 2006. COPD: the dangerous underestimate of 15\%. Lancet. 367:1216-1219.

6. Devereux, G. 2006. ABC of chronic obstructive pulmonary disease. Definition, epidemiology, and risk factors. BMJ. 332:1142-1144.

7. Martorana, P.A., et al. 1993. The pallid mouse. A model of genetic alpha 1-antitrypsin deficiency. Lab. Invest. 68:233-241.

8. Hautamaki, R.D., Kobayashi, D.K., Senior, R.M. and Shapiro, S.D. 1997. Requirement for macrophage elastase for cigarette smoke-induced emphysema in mice. Science. 277:2002-2004

9. Kuro-o, M., et al. 1997. Mutation of the mouse klotho gene leads to a syndrome resembling ageing. Nature. 390:45-51.

10. Wert, S.E., et al. 2000. Increased metalloproteinase activity, oxidant production, and emphysema in surfactant protein D gene-inactivated mice. Proc. Natl. Acad. Sci. U. S. A. 97:5972-5977.

11. Smith, C.A., and Harrison, D.J. 1997. Association between polymorphism in gene for microsomal epoxide hydrolase and susceptibility to emphysema. Lancet. 350:630-633.

12. Rangasamy, T., et al. 2004. Genetic ablation of Nrf2 enhances susceptibility to cigarette smoke-induced emphysema in mice. J. Clin. Invest. 114:1248-1259. doi:10.1172/JCI200421146.

13. Kaisho, T., and Akira, S. 2006. Toll-like receptor function and signaling. J. Allergy Clin. Immunol. 117:979-987; quiz 988.

14. Lappalainen, U., Whitsett, J.A., Wert, S.E., Tichelaar, J.W., and Bry, K. 2005. Interleukin-1beta causes pulmonary inflammation, emphysema, and airway remodeling in the adult murine lung. Am.J. Respir. Cell Mol. Biol. 32:311-318.

15. Lee, C.G., et al. 2004. Vascular endothelial growth 
factor (VEGF) induces remodeling and enhances TH2-mediated sensitization and inflammation in the lung. Nat. Med. 10:1095-1103.

16. Zheng, T., et al. 2000. Inducible targeting of IL-13 to the adult lung causes matrix metalloproteinase- and cathepsin-dependent emphysema. J. Clin. Invest. 106:1081-1093.

17. Zheng, T., et al. 2005. Role of cathepsin S-dependent epithelial cell apoptosis in IFN-gammainduced alveolar remodeling and pulmonary emphysema. J. Immunol. 174:8106-8115.

18. Barnes, P.J., Shapiro, S.D., and Pauwels, R.A. 2003. Chronic obstructive pulmonary disease: molecular and cellular mechanisms. Eur. Respir. J. 22:672-688.

19. Stoller, J.K., and Aboussouan, L.S. 2005. Alpha1antitrypsin deficiency. Lancet. 365:2225-2236.

20. Shapiro, S.D. 2002. Proteinases in chronic obstructive pulmonary disease. Biochem. Soc. Trans. 30:98-102

21. Elkington, P.T., and Friedland, J.S. 2006. Matrix metalloproteinases in destructive pulmonary pathology. Thorax. 61:259-266.

22. Finlay, G.A., et al. 1997. Matrix metalloproteinase expression and production by alveolar macrophages in emphysema. Am. J. Respir. Crit. Care Med. 156:240-247.

23. Demedts, I.K., et al. 2006. Elevated MMP-12 protein levels in induced sputum from patients with COPD. Thorax. 61:196-201.

24. Taggart, C., et al. 2000. Oxidation of either methionine 351 or methionine 358 in alpha 1-antitrypsin causes loss of anti-neutrophil elastase activity. J. Biol. Chem. 275:27258-27265.

25. Zhang, X., Shan, P., Sasidhar, M., Choi, A.M.K., and Lee, P.J. 2003. Reactive oxygen species and ERKmitogen activated protein kinase mediate hyperoxia-induced apoptosis in lung epithelium. Am. J. Resp. Cell Mol. Biol. 28:305-315.

26. Becker, L.B., vanden Hoek, T.L., Shao, Z.H., Li, C.Q., and Schumacker, P.T. 1999. Generation of superoxide in cardiomyocytes during ischemia before reperfusion. Am. J. Physiol. 277:H2240-H2246.

27. Li, J.M., Mullen, A.M., and Shah, A.M. 2001. Phenotypic properties and characteristics of superoxide production by mouse coronary microvascular endothelial cells. J. Mol. Cell. Cardiol. 33:1119-1131.

28. Pratico, D., et al. 1998. Chronic obstructive pulmonary disease is associated with an increase in urinary levels of isoprostane F2alpha-III, an index of oxidant stress. Am. J. Respir. Crit. Care Med. 158:1709-1714.

29. Kasahara, Y., et al. 2000. Inhibition of VEGF receptors causes lung cell apoptosis and emphysema. J. Clin. Invest. 106:1311-1319.

30. Yokohori, N., Aoshiba, K., and Nagai, A. 2004. Increased levels of cell death and proliferation in alveolar wall cells in patients with pulmonary emphysema. Chest. 125:626-632.

31. Spurzem, J.R., and Rennard, S.I. 2005. Pathogenesis of COPD. Semin. Respir. Crit. Care Med. 26:142-153.

32. Tuder, R.M., et al. 2003. Oxidative stress and apoptosis interact and cause emphysema due to vascular endothelial growth factor receptor blockade. Am.J. Respir. Cell Mol. Biol. 29:88-97.

33. Crapo, J.D., Barry, B.E., Foscue, H.A., and Shelburne, J. 1980. Structural and biochemical changes in rat lungs occurring during exposures to lethal and adaptive doses of oxygen. Am. Rev. Respir. Dis. 122:123-143.

34. Kasahara, Y., et al. 2001. Endothelial cell death and decreased expression of vascular endothelial growth factor and vascular endothelial growth factor receptor 2 in emphysema. Am. J. Respir. Crit. Care Med. 163:737-744.

35. Lu, Q., Harrington, E.O., and Rounds, S. 2005. Apoptosis and lung injury. Keio J. Med. 54:184-189.

36. Toborek, M., and Hennig, B. 1993. Vitamin E attenuates induction of elastase-like activity by tumor necrosis factor-alpha, cholestan- 3 beta, 5 alpha, 6 beta-triol and linoleic acid in cultured endothelial cells. Clin. Chim. Acta. 215:201-211.

37. West, D.C., and Kumar, S. 1986. Elastase activity in capillary and aortic endothelial cells. Anticancer Res. 6:1069-1072.

38. Menashi, S., Hornebeck, W., Robert, L., and Legrand, Y. 1989. Elastase-like activity in cultured aortic endothelial cells. Thromb. Res. 53:11-18.

39. Laug, W.E., Weinblatt, M.E., and Jones, P.A. 1985 Endothelial cells degrade extracellular matrix proteins produced in vitro. Thromb. Haemost. 54:498-502.

40. Faure, E., et al. 2000. Bacterial lipopolysaccharide activates NF-kappaB through toll-like receptor 4 (TLR-4) in cultured human dermal endothelial cells. Differential expression of TLR-4 and TLR-2 in endothelial cells. J. Biol. Chem. 275:11058-11063.

41. Hougee, S., et al. 2006. Oral administration of the NADPH-oxidase inhibitor apocynin partially restores diminished cartilage proteoglycan synthesis and reduces inflammation in mice. Eur. J. Phar macol. 531:264-269.

42. Furukawa, S., et al. 2004. Increased oxidative stress in obesity and its impact on metabolic syndrome. J. Clin. Invest. 114:1752-1761. doi:10.1172/ JCI200421625.

43. Boldogh, I., et al. 2005. ROS generated by pollen NADPH oxidase provide a signal that augments antigen-induced allergic airway inflammation. J. Clin. Invest. 115:2169-2179. doi:10.1172/JCI24422.

44. Geiszt, M., and Leto, T.L. 2004. The Nox family of NAD(P)H oxidases: host defense and beyond. J. Biol. Chem. 279:51715-51718.

45. Lambeth, J.D. 2004. NOX enzymes and the biology of reactive oxygen. Nat. Rev. Immunol. 4:181-189.

46. Owen, C.A. 2005. Proteinases and oxidants as targets in the treatment of chronic obstructive pulmonary disease. Proc. Am. Thorac. Soc. 2:373-385.

47. Iizuka, T., et al. 2005. Nrf2-deficient mice are highly susceptible to cigarette smoke-induced emphysema. Genes Cells. 10:1113-1125.

48. Ishii, Y., et al. 2005. Transcription factor Nrf2 plays a pivotal role in protection against elastase-induced pulmonary inflammation and emphysema. J. Immunol. 175:6968-6975.

49. Babior, B.M., Lambeth, J.D., and Nauseef, W. 2002. The neutrophil NADPH oxidase. Arch. Biochem. Biophys. 397:342-344.

50. Ueyama, T., Geiszt, M., and Leto, T.L. 2006. Involvement of Rac1 in activation of multicomponent Nox1- and Nox3-based NADPH oxidases. Mol. Cell. Biol. 26:2160-2174.

51. Griendling, K.K., Sorescu, D., and Ushio-Fukai, M. 2000. NAD(P)H oxidase: role in cardiovascular biology and disease. Circ. Res. 86:494-501.

52. Zalba, G., et al. 2001. Oxidative stress in arterial hypertension: role of $\mathrm{NAD}(\mathrm{P}) \mathrm{H}$ oxidase. Hypertension. 38:1395-1399.

53. Yang, S., Madyastha, P., Bingel, S., Ries, W., and Key, L. 2001. A new superoxide-generating oxidase in murine osteoclasts. J. Biol. Chem. 276:5452-5458.

54. Jones, S.A., Hancock, J.T., Jones, O.T., Neubauer, A., and Topley, N. 1995. The expression of NADPH oxidase components in human glomerular mesangial cells: detection of protein and mRNA for p47phox, p67phox, and p22phox. J. Am. Soc. Nephrol. 5:1483-1491.

55. Shiose, A., et al. 2001. A novel superoxide-producing NAD(P)H oxidase in kidney. J. Biol. Chem. 276:1417-1423.

56. Radeke, H.H., et al. 1991. Functional expression of NADPH oxidase components (alpha- and betasubunits of cytochrome b558 and 45-kDa flavoprotein) by intrinsic human glomerular mesangial cells. J. Biol. Chem. 266:21025-21029.

57. Cheng, G., Cao, Z., Xu, X., van Meir, E.G., and Lambeth, J.D. 2001. Homologs of gp91phox: cloning and tissue expression of Nox3, Nox4, and Nox5.
Gene. 269:131-140

58. Paffenholz, R., et al. 2004. Vestibular defects in headtilt mice result from mutations in Nox3, encoding an NADPH oxidase. Genes Dev. 18:486-491.

59. Banfi, B., et al. 2004. NOX3, a superoxide-generating NADPH oxidase of the inner ear. J. Biol. Chem. 279:46065-46072.

60. MacNee, W.2005. Pathogenesis of chronic obstructive pulmonary disease. Proc. Am. Thorac. Soc. 2:258-266; discussion 290-291.

61. Shapiro, S.D., et al. 2003. Neutrophil elastase contributes to cigarette smoke-induced emphysema in mice. Am. J. Pathol. 163:2329-2335.

62. Platt, M.O., Ankeny, R.F., and Jo, H. 2006. Laminar shear stress inhibits cathepsin Lactivity in endothelial cells. Arterioscler. Thromb. Vasc. Biol. 26:1784-1790.

63. Mueller-Anneling, L., Avol, E., Peters, J.M., and Thorne, P.S. 2004. Ambient endotoxin concentrations in PM10 from Southern California. Environ. Health Perspect. 112:583-588.

64. Klut, M.E., et al. 1996. Neutrophil activation and lung injury associated with chronic endotoxemia in rabbits. Exp. Lung Res. 22:449-465.

65. Stolk, J., et al. 1992. Induction of emphysema and bronchial mucus cell hyperplasia by intratracheal instillation of lipopolysaccharide in the hamster. J. Pathol. 167:349-356.

66. Eisenbarth, S.C., et al. 2002. Lipopolysaccharideenhanced, toll-like receptor 4-dependent $\mathrm{T}$ helper cell type 2 responses to inhaled antigen. J. Exp. Med. 196:1645-1651.

67. Rakoff-Nahoum, S., Paglino, J., Eslami-Varzaneh, F., Edberg, S., and Medzhitov, R. 2004. Recognition of commensal microflora by toll-like receptors is required for intestinal homeostasis. Cell. 118:229-241.

68. Adachi, O., et al. 1998. Targeted disruption of the MyD88 gene results in loss of IL-1- and IL-18-mediated function. Immunity. 9:143-150.

69. Hoshino, K., et al. 1999. Cutting edge: Toll-like receptor 4 (TLR4)-deficient mice are hyporesponsive to lipopolysaccharide: evidence for TLR4 as the Lps gene product. J. Immunol. 162:3749-3752.

70. D'Agostini, F., Balansky, R.M., Camoirano, A., and De Flora, S. 2005. Modulation of light-induced skin tumors by $\mathrm{N}$-acetylcysteine and/or ascorbic acid in hairless mice. Carcinogenesis. 26:657-664.

71. Hart, B.A., Elferink, J.G., and Nibbering, P.H. 1992. Effect of apocynin on the induction of ulcerative lesions in rat skin injected with tubercle bacteria. Int. J. Immunopharmacol. 14:953-961.

72. Cohn, L., Herrick, C., Niu, N., Homer, R., and Bottomly, K. 2001. IL-4 promotes airway eosinophilia by suppressing IFN-gamma production: defining a novel role for IFN-gamma in the regulation of allergic airway inflammation. J. Immunol. 166:2760-2767.

73. Lee, P.J., et al. 2006. ERK1/2 mitogen-activated protein kinase selectively mediates IL-13-induced lung inflammation and remodeling in vivo. J. Clin. Invest. 116:163-173. doi:10.1172/JCI25711.

74. Kuhlencordt, P.J., et al. 2004. Role of endothelial nitric oxide synthase in endothelial activation: insights from eNOS knockout endothelial cells. Am. J. Physiol. Cell Physiol. 286:C1195-C1202.

75. Zhang, X., et al. 2004. Small interfering RNA targeting heme oxygenase- 1 enhances ischemiareperfusion-induced lung apoptosis. J. Biol. Chem. 279:10677-10684.

76. Rust, L., Messing, C.R., and Iglewski, B.H. 1994. Elastase assays. Methods Enzymol. 235:554-562.

77. Klumpp, T., and Bieth, J.G. 1979. Automated measurement of the elastase-inhibitory capacity of plasma with a centrifugal analyzer. Clin. Chem. 25:969-972.

78. Cavarra, E., et al. 2001. Effects of cigarette smoke in mice with different levels of alpha(1)-proteinase inhibitor and sensitivity to oxidants. Am. J. Respir. Crit. Care Med. 164:886-890. 